\title{
QUE É ARTIFICAÇÃO?
}

\section{Roberta Shapiro*}

\begin{abstract}
Resumo: Há um aumento constante na produção de arte na sociedade e na pesquisa sobre arte e cultura dentro das ciências sociais. Conseqüentemente, parece apropriado propor a artificação como um campo novo para a Sociologia da Arte e da mudança social e cultural. A artificação é a transformação da não-arte em arte. Isto consiste em um processo social complexo da transfiguração das pessoas, das coisas e das práticas. A artificação não somente tem a ver com mudança simbólica, deslocamento de hierarquias e legitimidade, mas, implica, também modificações muito concretas nos traços físicos e nas maneiras das pessoas, nas formas de cooperação e organização, nos bens e nos artefatos que são usados, etc. Esses processos redefinem os limites entre a arte e a não-arte, e reconstróem mundos sociais novos. Neste artigo, são utilizados como exemplos de artificação o hip-hop, a fonografia, a gravura, a água-forte, o trabalho industrial e a arte primitiva.
\end{abstract}

Palavras-chave: arte, artificação, mudança cultural, cultura, arte da mudança social, mudança cultural, cultura, mudança social.

A artificação é a transformação da não-arte em arte. A constatação do aumento geral da atividade artística e do dinamismo da produção em ciências sociais que lhe é consagrada nos encoraja a propor a artificação como um novo campo de investigação para a sociologia da arte e da mudança social. ${ }^{1}$

\footnotetext{
Socióloga e chefe de pesquisa do Laboratório de Antropologia e História do Instituto de Cultura (LAHIC IA 8177), Centro de Estudos do Emprego (CEE), Paris - França.

Tradução do original Qu'est-ce que l'artification? por Ana Liési Thurler e revisão de Marisa Liebaut.

Uma primeira versão deste texto foi apresentada em 5 de julho de 2004, no XVI Congresso da Associação Internacional de Sociologia da Língua Francesa (AISLF), em Tours, França.

Artigo recebido em 23 ago. 2006 e aprovado em 21 out. 2006.
} 
Desejamos propor algumas pistas de reflexão a partir de uma idéia muito simples: a arte não é somente um corpus de objetos definidos por instituições e disciplinas consagradas, mas também o resultado desses processos sociais, datados e situados. Compreender o engendramento desses processos e descrever minuciosamente seu desenvolvimento poderá nos ajudar a clarificar a natureza dos objetos "de arte" e dos mundos sociais nos quais eles emergem ou, até mesmo, de mundos sociais resultantes desses objetos.

O neologismo, recente e pouco utilizado, vindo do inglês, às vezes se reveste de uma conotação depreciativa: a artificação seria a fabricação do artificial, compreendida como uma operação de mercantilização destruidora da autenticidade das coisas e dos atos. Não é esse o sentido adotado aqui. Tomamos o termo em uma acepção puramente descritiva.

$\mathrm{O}$ crescimento da atividade artística tem inerente um aspecto prático e um aspecto simbólico. Nas sociedades ocidentais, a demografia das profissões artísticas tem conhecido um aumento constante nas ultimas décadas, verificando-se um aumento igualmente significativo no que diz respeito à prática amadora (Donnat 1996, Coulangeon 2005). Além disso, o ideal do trabalho artístico - autônomo, expressivo, exigente, fonte de realização pessoal - é um modelo cada vez mais invocado em uma sociedade em que o nível global de formação aumenta, a intelectualização das operações de produção é cada vez maior e as formas de exercício da autoridade se distanciam da estrita subordinação hierárquica. Além disso, as instituições da cultura se desenvolvem continuamente, tanto a partir da ação pública, como de uma economia de mercado. A artificação participa de um movimento geral de objetivação da cultura, atingindo todas as sociedades.

Nossa hipótese é que esse desenvolvimento é, em parte, fruto da extensão das artes estabelecidas, mas não só. Ele surge também 
em processos de artificação, por meio dos quais nascem novas artes.

Focaremos nossa atenção nesse segundo aspecto. A artificação é o processo pelo qual os atores sociais passam a considerar como arte um objeto ou uma atividade que eles, anteriormente, não consideravam como tal.

A atribuição da nova categoria (arte) é acompanhada por uma transfiguração das pessoas, dos objetos, das representações e da ação. O processo é, ao mesmo tempo, simbólico e prático, discursivo e concreto. Trata-se de requalificar as coisas e de enobrecê-las: o objeto torna-se arte; o produtor torna-se artista; a fabricação, criação; os observadores, público, etc. As renomeações ligadas à artificação indicam também mudanças concretas, como a mudança do conteúdo e da forma de uma atividade, a transformação das qualidades físicas das pessoas, a reconstrução das coisas, a importação de novos objetos e a reestruturação dos dispositivos organizacionais. Trata-se, pois, de outra coisa, diferente de uma simples legitimação. O conjunto desses processos - materiais e imateriais - conduz ao deslocamento da fronteira entre arte e não-arte, bem como à construção de novos mundos sociais, povoados por entidades inéditas, cada vez mais numerosas.

\section{Condições e pressupostos da artificação}

O pressuposto elementar da artificação é o da crença no valor superior da arte. Essa crença, por sua vez, se desenvolveu mediante a constituição da categoria de arte, uma categoria datada e situada. Graças a trabalhos recentes, sabemos que a categoria de arte foi construída e estabilizada na Europa ocidental, entre os séculos XVII e XIX. Esse processo foi concomitante com um outro: o da criação, em cada esfera de atividade, de uma instituição reguladora - a Academia -, e de um corpus de obras e de carreiras 
canônicas que estabeleceram uma barreira entre os artistas e os outros (especialmente os artesãos e os amantes de arte). Outro aspecto determinante no processo de constituição da categoria de arte foram as transformações sociais que desfizeram a dependência dos artistas em relação aos aristocratas, permitindo a constituição de um mercado, de um público e de uma "estética" (Weber, 1975; Schaeffer, 1992; Heinich, 1993; Shiner, 2001).

Ao contrário, o século XX não conhece mais o cânone único e vê as instâncias de regulação e de reconhecimento se multiplicarem. Esse século se caracteriza por um processo incessante de absorção de formas novas em arte (Zolberg \& Cherbo, 1997). A fronteira não cessa de ser redefinida e a corrida ao valor parece não ter fim (Heinich, 1998).

Entre as condições que tornam esse processo possível e explicam sua extensão, duas delas colocam destaque sobre a arte como atividade (e não tanto como objeto) e sobre a multiplicação das instâncias de legitimação. Isso tem implicações significativas.

Fica estabelecida, doravante, a existência de uma multiplicidade de instâncias de reconhecimento e de regulação da arte. Não é mais a Academia que faz o artista, mas o público, os jornalistas, os livros e revistas, os colecionadores, os júris, os diretores de galeria ou de festival, as comissões de atribuição de subvenções, as instituições públicas ou privadas que solicitam os artistas, os estatísticos, os historiadores e os sociólogos, as caixas de aposentadorias e de seguro-saúde, os recenseamentos, etc. Segmentos cada vez mais numerosos e diversificados da população estão engajados na artificação e, em certas circunstâncias, dela tiram partido. Tudo isso contribui para explicar o fato de as formas de arte serem cada vez mais variadas e inesperadas. Sabe-se a que ponto a ação dos marchands e dos críticos no século XIX contribuiu para o fim do sistema acadêmico na pintura e na escultura. No século XX 
pode-se identificar outros intermediários ou "empreendedores de arte", que vêm questionar as categorias existentes e oferecer novos espaços para a incubação do valor artístico. São mencionados, por exemplo, pintores, médicos e diretores de museu, no caso da arte dos pacientes internados em manicômios (Bowle, 1997); preceptores, missionários e agentes do governo, no caso da arte aborígine da Austrália (de Roux, 2004; Barou \& Crossman, 2004); trabalhadores sociais, educadores, funcionários e diretores de teatro, no caso da dança hip-hop (Shapiro, 2004b); antropólogos, colecionadores e diretores de museu, no caso da arte africana (Errington, 1998); trabalhadores, seus familiares e vizinhos, conselheiros municipais, diretores de museus, no caso da "arte singular" (Moulinié, 1999); industriais, engenheiros de som, jornalistas e amantes de música, no caso da fonografia (Maisonneuve, 2001); etc. No caso da França, é notório o papel dos agentes do Estado, em todos os níveis do poder público, das municipalidades às administrações centrais, passando pelos poderes estaduais e regionais.

Há mais intermediários, mas há, igualmente, segmentos da população cada vez mais numerosos e diversificados, ou seja, mais postulantes ao estatuto de artistas. Como já referimos anteriormente, o número de artistas reconhecidos continua aumentando. Além disso, membros de grupos dominados e marginalizados acedem, por via da arte, a uma nova dignidade social: os povos outrora colonizados, as minorias étnicas, os excluídos do mundo do trabalho, os grupos sociais minoritários, etc. A expressão americana outsider art dá conta desse fenômeno. Esses novos artistas podem, entretanto, também ser detentores de uma capacidade técnica ou de uma competência particular que, em um determinado contexto (o desenvolvimento de um novo setor econômico, por exemplo), será requalificada e valorizada. É precisamente o que se verifica em disciplinas como o video art (Giallu, 1999; Lewine, 2005) ou a arte informática (Fourmentraux, 2005). 
$\mathrm{O}$ aumento do número e da diversidade social das pessoas envolvidas nos processos de artificação implica não só uma eventual intensificação das lutas de interesses, mas também a multiplicação dos tipos de recursos, de objetos técnicos, de redes de interconhecimento, de visões de mundo, etc., que são mobilizados e que, até então, eram inéditos no mundo da arte.

Segundo ponto a destacar: a ênfase passou a ser colocada sobre a arte como atividade mais do que como objeto. Tal ênfase pode estar relacionada com a "virada pós-moderna" dos mundos da arte depois de 1960 e com a banalização das performances (Huyssen, 1986), mas também com as transformações globais da concepção da pessoa em nossas sociedades (de Singly, 2000; Dubar, 2000). Segundo essa concepção, todos os indivíduos são portadores de uma autenticidade profunda, cuja realização expressiva é legítima e que pode ser, legitimamente, tornada pública. Sob essa relação todos são iguais. A arte, como expressão do eu profundo no espaço público, é uma das vias privilegiadas dessa realização, tendo a valência de afirmação identitária dos indivíduos e grupos. Assim, a artificação é uma das modalidades de um processo mais geral de objetivação e de instituição da cultura, que se apóia sobre a injunção geral da realização de si. Tal processo é definido por Daniel Fabre como “colocação à distância, pelas sociedades, de um certo número de objetos, de práticas e de saberes, constituídos em reservatórios de signos para a identificação coletiva e individual" (Ciarcia, 2001).

\section{Vigiar as fronteiras, palmilhar os espaços}

Quanto à indeterminação atual das fronteiras dos mundos da arte, V. Zolberg e J. M. Cherbo (1997) assim concluem: “a transgressão e a preservação das fronteiras coexistem em um estado de tensão crônica". Essa assertiva pode ser reformulada de modo mais preciso, se focarmos mais a atenção sobre o funcionamento 
dos espaços do que sobre as fronteiras que os delimitam. Eu diria antes que se verifica a coexistência de vários paradigmas de ação, uns assentados mais na transgressão, outros enfatizando mais a permanência das fronteiras. Na França, os dois paradigmas principais são a democracia cultural e a democratização cultural, mas em outras sociedades existem paradigmas análogos sob outras formas.

O primeiro é um paradigma antropológico, segundo o qual a arte é a expressão de grupos ou indivíduos social e espacialmente situados, cujo desenvolvimento está ligado, entre outras concepções, à concepção de pessoa que evocamos anteriormente. Conforme esse modelo, as transgressões das fronteiras da arte são feitas em nome do direito de expressão, da autenticidade artística e da restauração da dignidade desrespeitada de uma pessoa ou grupo. Na França, ela se traduz, regra geral, nos termos da democracia cultural, uma das orientações da ação pública.

O outro participa do paradigma da conversão à "boa" cultura (Passeron, 1990), segundo o qual a arte consiste em um corpus de obras ahistóricas, com valor universal, independente das propriedades sociais de seus autores, sendo necessário favorecer o acesso a essas obras ao maior número de pessoas. A manutenção das fronteiras se faz em nome da integridade desse corpus e dos valores de solidariedade que ele exprime. Na França, na linguagem de ação pública, isso se traduz por "democratização cultural". ${ }^{2}$ Assim, conforme Michel Melot (2004), a artificação é, também, a entrada no discurso da história da arte. Essa é a exata preocupação de certos dançarinos hip-hop: "O hip-hop é um redemoinho na história da arte", diz um dançarino e coreógrafo de 35 anos, responsável por uma companhia no subúrbio parisiense.

As duas orientações são projetos políticos, haja ou não envolvimento do Estado. Em um caso, a artificação se traduzirá 
pela exaltação pública de uma expressão nova. Em outro, pelo enriquecimento do corpus das obras legítimas. Ambas são tiposideais, dando lugar a uma infinidade de ações muito mais complexas que, em momentos distintos, conforme as pessoas envolvidas, integram elementos de um tipo ou de outro, assim como juízos divergentes sobre seu sentido e valor. A dança hip-hop dá bons exemplos dessas variações: um dado gestual que, em um momento, foi expressão de um grupo social dominado, transformou-se e deve ser integrado, segundo alguns, ao repertório da dança contemporânea, pensada como universal e colocada à disposição de todos (Shapiro, 2004a). Ou seja, nesse exemplo, o efeito da democracia cultural é enriquecer o corpus das obras que a democratização deve tornar acessíveis. Para outros, a dança hip-hop permanece uma expressão específica e menor, tendo uma virtude educativa como via de acesso à Grande Arte (Lafargue, 2003). Nesse caso, a democracia cultural está submetida aos imperativos da democratização. Eis um exemplo da passagem de um modelo de ação a outro e, ao mesmo tempo, de interpretações divergentes dos dois modelos.

Isso que acabei de propor é uma classificação no meio de outras classificações possíveis. Ela coloca ênfase sobre os aspectos políticos das transformações e sobre a arte como uma questão de interesses sem, contudo, abranger totalmente a paleta de significações que os atores dão às pessoas, aos objetos e às situações. Com efeito, encontramos uma visão diferente de artificação no trabalho de Véronique Moulinié. Ela examina diferentes sentidos de beleza e do artístico no sistema de trocas do cotidiano que ligam parentes, amigos e "trabalhadores", esses produtores de uma "arte singular", procedente da peruca operária que começa a interessar colecionadores e diretores de museus (Moulinié, 1999). 


\section{Uma artificação sem fim?}

Resta a questão da corrida ao valor, e disso que parece ser a tendência à extensão infinita dos mercados de arte, em nome dos valores de singularidade ou de autenticidade.

O processo que Nathalie Heinich descreveu como arte contemporânea encontra seu correspondente no caso da "arte étnica": "A raridade do 'verdadeiro' leva à produção e à reclassificação de artefatos para o mercado, artefatos esses que materializam, em configurações diferentes, categorias mais antigas. Novos tipos de artefatos vêm preencher espaços conceituais préexistentes do autêntico, do étnico/natural/primitivo e da arte (ou do artístico), em diversas permutações e combinações desses três atributos. A mercantilização se opera segundo a teoria clássica do resíduo: objetos e classes de objetos, em outro tempo invisíveis (os "resíduos"), tornam-se objetos que circulam, a saber, mercadorias. E algumas delas se tornam objetos duráveis. O mercado, as políticas de revival cultural e artístico, bem como os trabalhos universitários, todos promovem e legitimam essas produções e essas novas reclassificações" (Errington, 1998).

Como a arte contemporânea, a arte primitiva - rebatizada arte étnica, arte tribal, ou arte primeira - vê sem cessar suas fronteiras alargadas. Notam-se processos análogos para os objetos técnicos obsoletos ou para as produções artesanais nas sociedades ocidentais (por exemplo, valorizando velhos instrumentos e máquinas). Por isso, não se percebe em nome de quê a tendência geral à artificação deveria atingir seu limite de uma vez por todas, pois "tudo que comporta a marca da mão humana" é suscetível de ser redefinido como arte (Joseph Alsop, citado por Zolberg \& Cherbo, 1997).

Eis porque é particularmente interessante se debruçar não somente sobre a artificação e a maneira como ela interroga as categorias e as definições de fronteira, mas também sobre a resistência à artificação, a desartificação e a artificação inacabada. 


\section{Que limites para a artificação?}

A história dos gravadores do século XVIII, do estereógrafo e do fonógrafo no século XX alimentam os exemplos de desartificação ou de artificação inacabada.

$\mathrm{Na}$ época em que a distinção entre artesanato e arte estava pouco consolidada, os gravadores ingleses (reproductive etchers) valeram-se do estatuto de artistas durante algum tempo. No entanto, diante da oposição de pintores, o ingresso à Academia Real foi-lhes negado, com a justificativa da falta de originalidade de sua prática. Em seguida, a gravura de reprodução entrou em um período de declínio (Fyfe, 2000). Do mesmo modo, Howard Becker se pergunta porque as estereografias, que conheceram grande desenvolvimento nos anos 1920-30, não se tornaram obras de arte, como sucedeu com a fotografia. Os fabricantes não souberam diversificar a produção; ela permaneceu à margem do mundo da arte, desaparecendo em seguida. Se seguirmos esse autor, pensaremos que o declínio desse mundo social foi devido ao enfraquecimento dos laços de cooperação e de organização que o estruturavam (Becker, 1988).

Os trabalhos de Sophie Maisonneuve (2001) sobre a "máquina falante" mostram como esse novo objeto técnico vem enriquecer o mundo da música clássica, na primeira parte do século XX. Ainda que no início fora destinado a um uso administrativo (modelo do que mais tarde seria o gravador), o gramofone foi batizado como "instrumento de música", por analogia com o piano. Desenvolve-se um dispositivo social de organização da escuta: sessões em grandes auditórios, conforme o modelo do concerto clássico, mas também criação de publicações especializadas, emergência de uma crítica especializada e de uma codificação progressiva das condições da boa recepção. Nessa fase, os melômanos amadores de discos desempenham um papel importante. 
Trata-se de uma artificação do uso e de uma artificação do objeto propriamente dito. Os fabricantes e os jornalistas comparam a fatura do gramofone com a fatura de produtores artesanais de instrumentos. Estabelecem equivalência entre o disco e o cantor (uma publicação dos anos vinte do século XX mostra um disco de platina e a fotografia de um cantor imponente, com a legenda: "Both are Caruso"). Na década seguinte, o gramofone passa por um processo de desartificação, se o podemos chamar assim, sendo redefinido como um simples vetor técnico para a difusão de uma música feita algures, contrariamente à gravação que, essa, se "artifica". Nos anos mais recentes, o gramofone é reinventado como instrumento musical: os DJs servem-se dele, utilizando técnicas como scratch ou sampling, sendo até equiparados, por alguns, a compositores-intérpretes. $\mathrm{O}$ toca-disco, tornado obsoleto como dispositivo de escuta da música gravada, é redefinido como instrumento de percussão nas novas classificações musicológicas.

Em seus trabalhos sobre as "pessoas muito talentosas" que, após um dia na fábrica, fazem estátuas para o jardim, transformam uma peça de motor em vaso de flores, torneiam madeira, produzem objetos surpreendentes, Véronique Moulinié (1999) evoca esses "artistas singulares" que têm a admiração de seus vizinhos e familiares. Ela sublinha a ambigüidade da relação desses artistas com os mundos do trabalho e da arte, mostrando também como suas criações são, ao mesmo tempo, continuidade e ruptura com o universo doméstico e o cotidiano. Aqui, a artificação e a resistência à artificação estão finamente imbricadas e mesclam vários registros de valor. Os "trabalhadores", em nome do trabalho, podem recusar a qualificação de artista. Seus descendentes podem recusá-la em nome de valores familiares. O colecionador, o conselheiro municipal e o jornalista emitirão juízos de valor sobre essas produções, em nome da estética, do respeito ao meio ambiente ou do desenvolvimento local. 
A dança hip-hop é um exemplo de uma artificação frágil e, ao mesmo tempo, de resistências à artificação. Na França, hoje em dia, essa atividade é reconhecida como uma disciplina artística, mas de modo diferente, consoante as pessoas. Alguns diretores de teatro e coreógrafos consagrados vêem na dança hip-hop uma corrente da dança contemporânea, um style particular, que eles gostam de integrar em suas produções cênicas. Os dançarinos e coreógrafos hip-hop de origem popular, ao contrário, vêem nessa dança um gênero artístico específico, que eles querem promover como tal. ${ }^{4}$ Para alguns, trata-se também de uma causa da qual eles são militantes. Outros, responsáveis por equipamentos culturais, consideram tratar-se de um gênero específico, mas menor, destinado aos jovens, mais próximo do circo e da acrobacia do que da arte; e é assim que eles a programam. Finalmente, para sair da perspectiva que eles estimam ser "política", há os que ainda dão um passo lateral, tentando construir uma dança hip-hop que, claramente, retoma o espetáculo esportivo popular, à semelhança da patinação artística ou da dança esportiva. Esses desacordos remetem, sem margem para dúvidas, a concorrências no mundo da dança e do espetáculo, a lutas pela distinção social, mas, também, ao sentido da arte para aqueles que a vivenciam. Assim, encontramos no setor privado e no setor público promotores da artificação e resistentes à artificação entre dançarinos hip-hop e responsáveis institucionais. Um "mundo da arte" da dança hip-hop se constitui, mas atravessado por correntes contrárias, puxando-o ora para o mundo das variedades, ora para $\mathrm{o}$ do esporte, para o mundo da ação social (Shapiro 2004b).

\section{Questões}

A reflexão sobre a artificação não decorre de uma curiosidade científica desencarnada. Procuramos compreender o sentido da crescente extensão do campo da cultura e a tendência à transformação infinita de objetos e atividades em patrimônio cultural e/ou arte. 
Pode-se falar na emergência de uma culture society (Morato, 2003), de uma sociedade em que é crescente a indeterminação das fronteiras da arte. Essas análises ligam-se a mudanças importantes que ocorreram no mundo do trabalho (entre outras: terceirização da economia, mobilização crescente dos saberes abstratos, exigência de inovação e de engajamento vocacional) e ao papel do Estado.

É necessário nos assegurarmos de que o processo é reconhecido e, então, multiplicar as pesquisas empíricas. ${ }^{3}$ Para tentar compreendê-lo, é igualmente necessário multiplicar os ângulos de ataque. A extensão ou a instituição da cultura pode ser analisada como uma intensificação da produção de signos identitários coletivos e individuais (Fabre, apud Ciarcia 2001), quando fortes mudanças socioeconômicas desestabilizam as identidades tradicionais: na família, no mundo do trabalho, no domínio das crenças, e os laços comunitários se enfraquecem em prol das relações societárias (Dubar 2000). A arte e a cultura surgem, então, como atividades de compensação, permitindo constituir uma comunidade e restaurar a identidade individual. Podemos analisar a artificação também de um ponto de vista socioeconômico, nos colocando algumas perguntas. Em que ações desemboca o discurso em torno da criatividade e do engajamento no trabalho? Em que condições elas aprofundam a exploração ou, ao contrário, oferecem espaços de liberdade às pessoas? (Boltanski \& Chiapello 2000).

Pode-se, igualmente, tentar compreender a artificação em sua relação com a política e o enfraquecimento das funções tradicionais de integração e de proteção asseguradas pelo Estado-providência. $\mathrm{Na}$ França, a questão da importância da arte e da cultura foi, por vezes, controversa, mas, atualmente, a crença em seu papel socializador é senso comum, em grande parte da instituição estatal. Quando se constata o enfraquecimento "dos domínios clássicos da socialização" que são "a família e a empresa", dispositivos de "disciplinarização das condutas" e, ao mesmo tempo, de construção 
de solidariedades (Donzelot \& Estèbe, 1994), fica-se surpreso com o considerável investimento na arte e na cultura por uma parte dos agentes do poder público, e com o papel que eles desempenham na expansão de ambas.

\section{Notas}

1 Em sua tipologia da ação cultural, J.-C. Passeron (1990) definiu uma terceira modalidade: a revolução artística que pode subverter as condições mesmas da produção artística e abolir a fronteira entre arte popular e arte de elite.

2 Sobre a importância da distinção entre gênero e estilo, ver Heinich e Schaeffer (2004).

3 No grupo de trabalho sobre artificação do Laboratório de Antropologia, de História e de Instituição da Cultura (Lahic - Iiac Umr 8177), somos muitos a desenvolver um trabalho de reflexão e de acumulação sobre essas questões desde 2003. Cumprimento, aqui, os participantes do grupo pela qualidade das pesquisas e das discussões aí realizadas. $\mathrm{O}$ presente texto lhes deve muito.

\section{What is "artification"?}

Abstract: There is both a steady increase in the production of art in society and in research on art and culture within the social sciences. Therefore it seems appropriate to propose artification as a new field for the sociology of art and social and cultural change. Artification is the transformation of non-art into art. This consists of a complex social process of transfiguration of people, things and practices. Artification not only has to do with symbolic change, shifting hierarchies and legitimacy. It also implies very concrete modifications in people's physical traits and manners, in ways of cooperating and organizing, in the goods and artifacts that are used, etc. These processes redefine borders between art and non-art, and reconstruct new social worlds. In this article, we refer to examples 
of artification in the realms of hip-hop, phonography, etching, industrial labor, and primitive art.

Keywords: art, artification, cultural change, culture, social change art, artification, cultural change, culture, social change.

\section{Referências bibliográficas}

BAROU, Jean-Pierre; CROSSMAN, Sylvie. Enquête sur les savoirs indigènes. Paris: Gallimard Folio, 2005.

BOLTANSKI, Luc; CHIAPELLO, Eve. Le nouvel esprit du capitalisme. Paris: Gallimard, 2000. (NRF Essais).

BOWLER, Anne E. Asylum art: the social construction of an aesthetic category. In: ZOLBERG, V.; CHERBO, J. M. Outsider Art. New York: Cambridge University Press, 1997.

CIARCIA, Gaetano. Croire aux arts premiers. Gradhiva, n. 158-159, p. 339-352, avril/sept. 2001.

COULANGEON, Philippe. Les pratiques culturelles. Paris: La Découverte, 2005.

DONNAT, Olivier. Enquête sur les activités artistiques des Français. Paris: Dep. Documentation Française, 1996.

DONZELOT, Jacques; ESTÈBE, Philippe. L'Etat animateur: essai sur la politique de la ville. Paris: Esprit, 1994.

DUBAR, Claude. La crise des identités: l'interprétation d'une mutation. Paris: Puf, 2000.

ERRINGTON, Shelly. The death of authentic primitive art and other tales of progress. Berkely: Los Angeles: University of California Press, 1998.

FOURMENTRAUX, Jean-Paul. Art et Internet: les nouvelles figures de la création. Paris: CNRS, 2005. 
GIALLU, Revue d'art et de sciences humaines, n. 5, 1995.

HEINICH, Nathalie. Du peintre à l'artiste. Paris: Minuit, 1993. . Le triple jeu de l'art contemporain. Paris: Minuit, 1998.

HEINICH, Nathalie; SCHAEFFER Jean-Marie. Art, création, fiction: entre Sociologie et Philosophie. Nîmes: Jacqueline Chambon, 2004.

HUYSSEN, Andréas. After the great divide: modernism, mass culture, postmodernism. Indiana: University Press, 1986.

LAFARGUE DE GRANGENEUVE, Loïc. L'opéra de Bordeaux, la danse hip-hop et ses publics. In: DONNAT, O. Le(s) public(s) de la culture. Paris: Presses de Sciences Pó, 2003.

LEWINE, Edward. Art that has to sleep in the garage. The New York Times, June 26, 2005.

MAISONNEUVE, Sophie. De la 'machine parlante' à l'auditeur: le disque et la naissance d'une nouvelle culture musicale dans les années 1920-30. Terrain, n. 37, sept. 2001.

MELOT, Michel. La métamorphose selon Malraux, communication. In: Séminaire du Laboratoire d'Anthropologie, d'Histoire et d'Institution de la Culture (Lahic). Paris: Ministère de la Culture, printemps, 2004.

MORATO, Arturo Rodriguez. The culture society: a new place for the arts in the twenty-first century. The Journal of Arts, Management, Law and Society, v. 32, n. 4, Winter, 2003.

MOULINIÉ, Véronique. Des 'œuvriers' ordinaires: lorsque l'ouvrier fait le/du beau. Terrain, n. 32, mars, 1999.

PASSERON, Jean-Claude. Le raisonnement sociologique. Paris: Nathan, 1990.

DE ROUX, Emmanuel. Les Aborigènes, peintres du temps. Le Monde, 8 avril, 2004. 
DE SINGLY, François. Libres ensemble: l'individualisme dans la vie commune. Paris: Nathan, 2000.

SHAPIRO, Roberta. La danse à l'envers. In: NAHOUM-GRAPPE, V.; VINCENT, O. Le goût des belles choses: Ethnologie de la relation esthétique, Paris: Maison des Sciences de l'Homme, 2004(a). . The aesthetics of institutionalization: breakdancing in France. The Journal of Arts Management, Law and Society, n. 33, Winter, 2004(b).

SHINER, Larry. The invention of art: a cultural history. Chicago: The University of Chicago Press, 2001.

WEBER, William. Music and the middle class: the social structure of concert life in London, Paris and Vienna. New York: Holmes \& Méier, 1975.

ZOLBERG, Vera; CHERBO, Joni Maya. Outsider art: contesting boundaries in contemporary culture. New York: Cambridge University Press, 1997. 